ANNUAL PERFORMANCE REPORT TO THE DEPARTMENT OF ENERGY

PROJECT DE-FGO2-89ER-14080

DEVELOPMENT OF AN EXPERIMENTAL DATA BASE AND THEORIES FOR PREDICTION OF. THERMODYNAMIC PROPERTIES OF AQUEOUS ELECTROLYTES AND NONELECTROLXTES OF GEOCHEMICAL SIGNIFICANCE AT SUPERCRITICAL TEMPERATURES AND PRESSURES

Robert H. Wood, Lubomir Hnedkovsky, and Ching Lung lin

Department of Chemistry and Biochemistry University of Delaware Newark, DE 19716

and

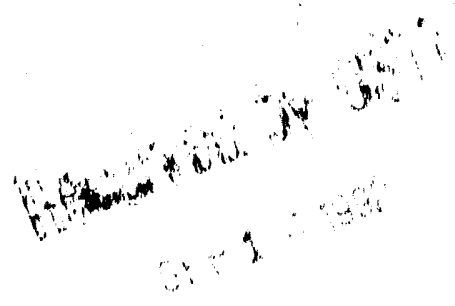

Everett. L. Shock

Department of Earth and Planetary Sciences

Washington University

St.Louts, MO 63130 


\section{Sunmary of Results}

Research under this project is divided Into three areas: experimental. measurements, theoretical development, and geochemical applications. We have completed experimental volumetric measurements on aqueous solutions of $\mathrm{CO}_{2}$, $\mathrm{H}_{2} \mathrm{~S}, \mathrm{CH}_{4}, \mathrm{NH}_{3}$ and $\mathrm{B}(\mathrm{OH})_{3}$ at 25 to $432^{\circ} \mathrm{C}$ and $\mathrm{p}-280$ and 350 bar. A new way of using our vibrating tube densitometer that allows density measurements near the bubble pofint and at the same time measures the bubble pressure was developed and used to measure densities and bubble pressures of aqueous $\mathrm{CO}_{2}$. Heat capacity measurements on the same compounds should be completed by the end of the grant pexiod.

On the theoretical side simulations of models for methane in water at cemperatures to $1000^{\circ}$ are in progress. In order to facllitate these free energy calculations the possible errors assoclated with the calculations have been explored in two papers (Wood, 1991; Wood et al., 1991) and methods of controliling and estimating these errors have been developed. The calculations on methane should be complete by the end of the grant period.

Experimental data collection is nr,w well along and applications of the new data to geochemical processes is now possible. Meanwhile, efforts in this area have focussed on extracting equilibrium constants for carbonic acid dissociation at supercritical condition from published experiments on mineral equilibrie in $\mathrm{H}_{2} \mathrm{O}-\mathrm{CO}_{2}$ fluids (Böhlke and Shock, 1990; and in prep.). As a result, estimates of pka for carbonic acid are now available at temperatures from $300^{\circ}$ to $750^{\circ} \mathrm{C}$ and pressures from 1 to 7 kilobars. These estimates will be combined with the $\overline{\mathrm{V}}^{\circ}$ and $\overline{\mathrm{C}}_{\mathrm{p}}{ }^{\circ}$ data for $\mathrm{CO}_{2}$ (aq) to improve the accuracy of thermodynamic data and mass-transfer calculations for geochemical repctions involving $\mathrm{CO}_{2}$ (aq). 


\section{INTRODUCTION}

A detalied analysis of the processes that lead to the formation, migration, and accumulation of petroleum hydrocarbons is of vital economic and strategic importance. So too is the ctudy of processes which govern the transport and deposition of metals and other inorganic species in sedimentary basins and in hydrothermal systems. Consideration of stable and metastable equilibria involving these aqueous specins, minerals, gases, and condensed phases (solid and 14quid) can lead to a more comprehensive understanding of a wide variety of geochemical processes, but requires accurate thermodynamic daca for aqueous species at high pressures and temperatures. The long-term goals of this research are tc create an experimental database and set of theoretical models which will allow accurate prediction of the thermodynamic properties of any aqueous solution component of significance to geochemical processes from normal surface conditions to the temperatures and pressures at which crustal rocks begin to melt. As a first step towards this goal we have measured volumes and are measuring heat capacities of aqueous solutions of $\mathrm{H}_{2} \mathrm{~S}, \mathrm{CO}_{2}, \mathrm{CH}_{4}, \mathrm{NH}_{3}$, and $\mathrm{H}_{3} \mathrm{BO}$, spectes of great geochemical significance. The second goal is to use this vastly expanded data. base to both test existing theories and predictive methods and to develop new and highly refined theoretical approaches. As a result of our measurements the available high temperature calorimetric and volumetric data on aqueous nonelectrolytes will be roughly tripled. The free energies at any temperature and pressure are readily calculated from the well known values of enthalpies and free energies at $298.15 \mathrm{~K}$ and 1 bar, together with heat capacities and volumes at a11 $\mathrm{T}$ and $\mathrm{P}$. Thus, the present measurements will yield more accurate values for free energies of these species from $25^{\circ} \mathrm{C}$ to $-430^{\circ} \mathrm{C}$.

An undertaking of this type overlaps the field of physical chemistry and geochemistry. The success of this project depends upon the interdisciplinary combination of the expertise of three of us (RHW, LH, and CLL) in making these types of high temperature measurements and using physical chemical theories to model the results, together with the expertise of the other author (ELS) in developing geochemicaliy applicable models for thermodynamic properties, fitting experimental data, and making extrapolations to higher temperatures and pressures, and finally applying the calculated thermodynamic properties to studies of the consequences of fluid/rock interactions.

\section{EXPERTMENTAI, MEASUREMENTS}

Before starting measurements on these solutions, it was convenient to first find methods of storing and dispensing aqueous solutions of the solute in such a way that the concentration didn't change rapidly with time. The $\mathrm{H}_{2} \mathrm{~S}$ and $\mathrm{CO}_{2}$ were stored in PVC pipes under a pressure of about 5 atm with the solutions being contained in an inner, aluminized mylar bag and expelled from the container by pumping water into the outer chamber of the vessel, thereby expelling the solution from inside the rylar bag. For methane, pressures of 100 bar are necessary, so we used a stainless steel bomb with a separator that moves up and down within the bomb to separate the aqueous methane solution from the driving fluid.

Heat capacity measurements are being measured with the flow, heat capacity apparatus developed previously (Biggerstaff et al., 1988; Carter and Wood, 1991). This apparatus measures the change in electric power necessary to keep the same temperature rise when switching from pure water to an aqueous solution in the flow strear. Recently this apparatus has been used to measure the heat 
capactites of aqueous electrolytes at pressures to $335 \mathrm{MPa}$ and cemperatures to and $425^{\circ} \mathrm{C}$ (Caxter, 1992).

The densities have been measured with a vibrating tube densimeter described previously (Majer et al., 1991), Briefly, the densimeter measures the density of the aqueous solution relative to the density of pure water at the same temperature and pressure by measuring the period of a vibrating tube filled with the solution. The apparatus is calibrated using pure water and helium gas under pressure. The difference in denstry between pure water and a solution can be measured with an accuracy of about $\pm 0.5 \%$ and with a sensitivity of about $10^{-4}$ $\mathrm{g} / \mathrm{cm}^{3}$.

\section{RESULTS}

The volumetric measurements on aqueous solutions of $\mathrm{CH}_{4}, \mathrm{CO}_{2}$, boric acid, ammonia, and $\mathrm{H}_{2} \mathrm{~S}$ at all temperatures and two or three pressures have been completed. Sorne preliminary measurements on aqueous carbon dioxide at high temperatures have been revised and published (Crovetto et al. 1991). The results of the other measurements are given in Table $I$ and are in the process of being written up for publication. Sorne typical results of the volumetric measurements are given in Figures 1-2. The results show apparent molar volumes (which are roughly proportional to the compressibility of pure water) which peaks near $400^{\circ} \mathrm{C}$ at $28 \mathrm{MPa}$. This same behavior was observed in earlier measurements in this laboratory on argon, ethylene and xenon (Biggerstaff and Wood, 1988) and in exploratory measurements on $\mathrm{CO}_{2}$ at high temperatures (Crovetto et al., 1990, 1991). This new volumetric data will allow reasonable extrapolation of the experimental solubilities of these gases at saturation pressure to high pressures. Solubilities of these gases have been measured up to about $350^{\circ} \mathrm{C}$ and the accuracy of the measurements is quite good up to $250^{\circ} \mathrm{C}$, but the measurements get much more difficult and less accurate above this temperature. The heat capacity data will. allow confirmation of these solubility results and calculation of the free energy of the aqueous specles up to $425^{\circ} \mathrm{C}$ with pressures to 350 bar by integration of the heat capacity and volume results.

Most of the previous volumetric measurements on nonelectrolytes have been confined to temperatures kelow $100^{\circ} \mathrm{C}$. Exceptions are (1) some previous measurements on argon, ethylene, and xenon from this laboratory, (2) boric acid, and (3) aqueous carbon dioxide at very high concentrations. The present results represent the first systematic exploration of the volumetric properties of aqueous nonelectrolytes at high temperatures. The importance of this kind of data is underscored by the failure of the best prediction schemes to accuratly predict these high temperature volumetric properties. For example, Figure 3 shows a comparison of measurements and predictions for $\overline{\mathrm{V}}^{\circ}$ of $\mathrm{CO}_{2}$ (aq) at 280 bar. It can be seen that the predictions of shock et al. (1989) are considerably lower than the measured values. This type cf discrepency is typical for the nonelectrolytes, and in the case of boric acid the predictions have the wrong sign. These kinds of failures are understandable because the authors had to rely on the room temperature data, a few high temperature equilibrium constants, and correlations based on previous measurements from this laboratory on argon, xenon and ethylene.

We have also used the vibrating tube densimeter to explore measurements on the bubble point of aqueous $\mathrm{CO}_{2}$ solutions at high temperatures. This is a way of measuring the solubility of gases in water: at high temperatures which is fairly easy and which gives accuracies that are not too bad near the critical 
point of water (approximately 10\% in Henry's constant) (Crovetto and Wood, 1992). While making these measurements, the densities of the solutions close to the bubble point were obtained with 10 times greater accuracy than any previous measurements.

\section{THEORETICAL MODELS}

The recent increases in computing power now allow a whole new approach to the prediction of the properties of very hlgh temperature aqueous solutions. Given a law of the forces between the atoms in the molecules of the solution, one can integrate Newton's laws of motion for these forces for say 300 molecules, allow thern to equilibrate at any temperature desired, and by appropriate averaging of the properties calculate all of the thermodynanic properties for this model system. Of course the model compounds are not the real world, but the models for these species are becoming more and more accurate and by fitting the models to experimental data at lower temperatures, one can then extrapolate these nodels of the forces between atoms to estimate the properties of real solutions. The sensitivity of the predictions to the model parameters can also be assessed. The extrapolations have the advantage that the forces between atoms in the real world are independent of: temperature.

We are primarily interested in the partial molar free energies of these gases at temperatures to $1000^{\circ} \mathrm{C}$. The advantage of this kind of calculation is that it can bo done at any temperature and pressure without any "experimental" problems. In a sense these are experimental results but in a model universe, that is, not the real universe.

One problem with these measurements is there have not been reliable ways to estimate the numerical accuracy with which free energies can be calculated by this procedure. Our first step in this project was to develop methods for estimating the systematic error due to the lag of the system configuration behind the Hamiltonian (Wood, 1991), and the systematic error due to the use of finite samples of configuration space in calculating the free energy (Wood et al., 1991)

Some preliminary results on equilibrium constant for methane solubility at high temperatures are given in Figure 4 which shows a contour plot of temperature vs. density on which the predicted equilibrium constants of Shock et al. (1989) are plotted against three experimental points with a Hamiltonian model simulation for methane. We are currently refining our Hamiltonian model so as to get the best possible estimates and then we"ll do a grid of predictions at high tempexatures and a variety of densities.

\section{DISCUSSION}

The volumetric measurement:s for aqueous nonelectrolytes described above permit revision of data and methods used to calculate thermodynatnic properties of these species in fluidudriven geochemical processes. We are presently pursuing two approaches to these revisions. First, the revised Helgeson-KirkhamFlowers (HKF) equations of state adopted by shock et al. (1989) for aqueous nonelectrolytes are being used to regress the new data and obtain revised equation-of-state parameters. These parameters will allow improvements in the accuracy of predicted thermodynamic data calculated with the revised HKF equation throug'nout crustal conditions. Revised parameters will be presented in a format which will allow easy updating of the data files for the SUPCR'T2 program 
(Johnson et al., 1991) recently made available to the geochemical community. These revisions should help resolve some existing inconsistenctes in nonelectrolyte properties as described below. Secondly, the new experimental data will be used to develop a new equation of state for geochemical calculations involving aqueous nonelectrolytes based on the density of $\mathrm{H}_{2} \mathrm{O}$ rather than on 1 ts dielectric constant. Such an equation of state should be more intrinsically appealing as it will eliminate the need to evaluate effective Born coefficients which imply that formally neutral aqueous specles have fractional charges. However, only if it retains and enhances predictive power will such an equation of state be as useful as the revised HKF equations for geochenical calculations. Therefore, considerable effort will go toward constructing correlations to estimate data for the multitude of nonelectrolytes (inorganic and organic) involved in geochemical processes for which experimental data may never be collected.

An example of the utility of the data already collected can be fllustrated by considering aqueous $\mathrm{CO}_{2}$. As shown in Figuxe 5 there is considerable divergence of calculated values of $\log \mathrm{K}$ for carbonic acid dissociation (curves) and those determined experimentally (symbols) at pressures other than the vaporliquid saturation pressures for $\mathrm{H}_{2} \mathrm{O}$ (Psat). The curves in Figure 4 were calculated with equations, data and parameters from Shock et al. (1989). Part of the problem has been revealed by the lack of agreement between predicted values of $\mathrm{V}_{2}{ }^{\circ}$ for $\mathrm{CO}_{2}$ and those measured as described above. Apparently, the magnitude of the effective Born coefficient obtained by Shock et al. (1989) by regression of $\mathrm{CO}_{2}$ solubility data together with the Psat data in Figure 4 is too low. New regression results indicate that this coefficient could be as much as an order of nlagnitude greater. These results help to identify the problem, but the complete solution will require the heat capacity measurenents currently underway.

Meanwhile, other lines of evidence confirm that the calculations shown in Figure 5 should be revised. Many metamorphic petrologists have conducted experiments to determine the effects of changing the mole fraction of $\mathrm{CO}_{2}$ in $\mathrm{CO}_{2}$ $\mathrm{H}_{2} \mathrm{O}$ fluids on the stabilities of mineral assemblages. The data collected at the lowest mole fractions of $\mathrm{CO}_{2}$, combined with thermodynamic data for minexals, $\mathrm{H}_{2} \mathrm{O}$ and other aqueous species, allow retrieval of well-constrained estinates of $\log$ $K$ for carbonic acid dissociation at supercritical conditions (Böhlke and Shock, 1990 ; and in prep.). These values of $\log \mathrm{K}$, which extend to temperatures above $600^{\circ} \mathrm{C}$ and pressures to $7 \mathrm{~kb}$, connect smoothly with Read's data shown in Figure 5. Combined regression of these $\log K$ estimates with the volumetxic and calorimetric data obtained in the present project will allow improved geochemical calculations with a new set of HKF parameters. As a result, it may be possible to reconcile differences in calculation methods and conceptual approaches to $\mathrm{CO}_{2}$ $\mathrm{H}_{2} \mathrm{O}$ fluids taken by aqueous geochemists and metamorphic petrologists. Applications of these results include studies of $\mathrm{CO}_{2}$ speciation in fluid inclusions, generation of gold-quartz veins in the Mother Lode of California, albite/carbonate metasomatism by sodium bicarbonate fluids, and many other metamorphic-hydrothermal processes. 


\section{REFERENCES}

Biggerstaff, D. R., White, D. E. and Wood, R. H. (1988) Apparent molar heat capacities of aqueous argon, ethylene, and xenon at temperatures up to $720 \mathrm{~K}$ and pressures to $33 \mathrm{MPa}$ J. Phys. Chem. 92, $1994-2000$.

Böhlke, J. K. and Shock, E. L. (1990) Carbonic acid dissociation in aqueous metamorphic fluids. (abs.) Geo1. Soc. Amer. Abstracts with Programs 22, A348.

Carter, R. W. and Wood, R. H. (1991) Calibration and sample measurement techniques for flow heat capacity calorimeters. I. Chem. Thermodynamies 23, $1037-1056$

Carter, R. W. (1992) Apparent molar heat capacities at constant pressure of 1:1 aqueous electrolytes from 598 to $691 \mathrm{~K}$ and 28 to $38 \mathrm{MPa}$, Ph.D.

Dissertation, University of Delaware, June 1992.

Crovetto, R. and Wood, R. H. (1992). Eluid Phase Equilibria, accepted.

Crovetto, R., Wood, R. H. and Majex, V. (1990) Densities of $\left(x \mathrm{CO}_{2}+(1-x) \mathrm{H}_{2} \mathrm{O}\right)$ with $x<0.014$ at supercritical conditions. Molar volumes, partial molar volumes of $\mathrm{CO}_{2}$ at infinite dilution, and excess molar volumes. J. Chem. Thermodynamics $22,231-243$.

Crovetto, R., Wood, R. H. and Majer, V. (1991) Revised densities of dilute aqueous $\mathrm{CO}_{2}$ mixtures of $\left\{\mathrm{xCO}_{2}+(1 \cdots \mathrm{x}) \mathrm{H}_{2} \mathrm{O}\right\}$ with $\mathrm{x}<0.014$ at supercritical conditions. Molar volume, partial molar volume of $\mathrm{CO}_{2}$ at infinite dilution, and excess volumes, by R. Crovetto, R. H. Wood and V. Majer, J.Chem. Thermodynamics 23, $1139-1146$.

Johnson, J. W., Oelkers, E. H. and Helgeson, H, C. (1992). SUPCRT92: A Software package for calculating the standard molal thermodynamic properties of minerals, gases, aqueous species, and reactions from 1 to 5000 bars and $0^{\circ}$ to $1000^{\circ} \mathrm{C}$. Earth Sciences Department, L-219, Lawrence Livermore National Laboratory, Livermore, CA 94550. 1992. submitted to Computers and Geoscience.

Majer, V., Crovetto, R. and Wood, R. H. (1991) A new version of vibratingtube flow densimeter for measuring up $00730 \mathrm{~K}$. J. Chem. Thermodynamics 23, $333-344$

Shock, E. L. and HeJgeson, H, C. (1990). Calculation of the thermodynamic and transport properties of aqueous species at high pressures and temperatures: Standard partial molal properties of organic species. Geochim. Cosmochim. Acta $54,915-945$.

Shock, E. L., Helgeson, H. C., and Sverjensky, D. A. (1989) Calculation of the thermodynamic and transport properties of aqueous species at high pressures and temperatures: Standard partial molal properties of inorganic neutral species Geochim. Cosmochim. Acta 53, 2157-2183.

Wood, R. H., Muehlbauer, W. C. F., and Thompson, P. T. (1991) Systematic errors in free energy perturbation calculations due to finite sample size: Sample-size hysteresis. J. Phys. Chem. 95, 6670-75. 
Wood, R. H. (1991) Estimation of errors in free energy calculations due to the lag between the Hamiltonian and the system configuration. J. Phys. Chem. $95,4838-42$. 
TABLE T.

$\mathrm{CH}+14$

Mon, Feb 3, 1992 11:53 PM

$\begin{array}{ccccc}\|^{\circ} \mathrm{C} & \text { P/MPa } & \text { molality } & \Delta d & V \text {-phi } \\ 25.00 & 28.00 & 0.140 & -3.01 & 37.16 \\ 50.00 & 28.00 & 0.140 & -2.98 & 37.50 \\ 100.00 & 28.00 & 0.140 & -3.18 & 40.71 \\ 150.00 & 28.00 & 0.140 & -3.49 & 46.01 \\ 200.20 & 28.00 & 0.140 & -3.93 & 54.39 \\ 250.00 & 28.00 & 0.111 & -3.46 & 65.50 \\ 300.00 & 28.00 & 0.137 & -5.41 & 92.65 \\ 350.00 & 28.00 & 0.138 & -7.86 & 167.55 \\ 379.90 & 28.00 & 0.138 & -15.17 & 462.89 \\ 384.03 & 28.00 & 0.131 & -16.93 & 608.54 \\ 387.19 & 28.00 & 0.132 & -20.15 & 817.86 \\ 390.27 & 28.00 & 0.132 & -24.35 & 1182.80 \\ 393.10 & 28.00 & 0.115 & -23.00 & 1624.97 \\ 394.96 & 28.00 & 0.114 & -20.59 & 1786.70 \\ 396.91 & 28.00 & 0.113 & -16.33 & 1753.70 \\ 401.38 & 28.00 & 0.112 & -8.05 & 1289.01 \\ 405.72 & 28.00 & 0.112 & -4.66 & 980.88 \\ 412.32 & 28.00 & 0.112 & -2.60 & 742.18 \\ 432.13 & 28.00 & 0.113 & -0.92 & 475.56 \\ & & & & \\ 25.00 & 35.00 & 0.140 & -2.91 & 36.28 \\ 50.00 & 35.00 & 0.140 & -2.95 & 37.11 \\ 100.00 & 35.00 & 0.140 & -3.15 & 40.28 \\ 150.00 & 35.00 & 0.140 & -3.50 & 45.85 \\ 200.00 & 35.00 & 0.140 & -3.93 & 53.83 \\ 250.00 & 35.00 & 0.111 & -3.42 & 64.13 \\ 300.00 & 35.00 & 0.137 & -5.16 & 87.26 \\ 350.00 & 35.00 & 0.138 & -6.62 & 136.14 \\ 395.08 & 35.00 & 0.114 & -8.80 & 342.33 \\ 412.44 & 35.00 & 0.114 & -10.48 & 681.73 \\ 421.83 & 35.00 & 0.113 & -7.61 & 761.39 \\ 432.30 & 35.00 & 0.113 & -4.06 & 630.66\end{array}$




$\begin{array}{rccccc} & T^{\circ} \mathrm{C} & \text { P/MPa } & \text { molality } & \Delta d & \text { V-phi } \\ 1 & 25.00 & 1.00 & 0.155 & 1.65 & 34.37 \\ 2 & 25.00 & 20.00 & 0.155 & 1.61 & 33.43 \\ 3 & 50.00 & 20.00 & 0.155 & 1.58 & 33.84 \\ 4 & 100.00 & 20.00 & 0.155 & 1.11 & 37.80 \\ 5 & 150.00 & 20.00 & 0.155 & 0.63 & 42.69 \\ 6 & 200.20 & 20.00 & 0.155 & 0.01 & 50.05 \\ 7 & 250.00 & 20.00 & 0.185 & -0.96 & 61.78 \\ 8 & 300.00 & 20.00 & 0.155 & -2.05 & 84.62 \\ 9 & 350.00 & 28.00 & 0.155 & -4.01 & 133.64 \\ 10 & 379.90 & 28.00 & 0.155 & -10.48 & 349.37 \\ 11 & 384.03 & 28.00 & 0.157 & -13.58 & 475.90 \\ 12 & 387.18 & 28.00 & 0.157 & -16.80 & 643.68 \\ 13 & 390.26 & 28.00 & 0.157 & -20.52 & 914.05 \\ 14 & 393.13 & 28.00 & 0.157 & -22.45 & 1256.77 \\ 15 & 395.03 & 28.00 & 0.157 & -20.42 & 1396.94 \\ 16 & 396.91 & 28.00 & 0.157 & -16.37 & 1382.08 \\ 17 & 401.37 & 28.00 & 0.157 & -7.90 & 1039.99 \\ 18 & 405.72 & 28.00 & 0.157 & -4.36 & 811.16 \\ 19 & 412.31 & 28.00 & 0.157 & -2.07 & 606.92 \\ 20 & 432.15 & 28.00 & 0.157 & -0.40 & 409.20 \\ 21 & & & & & \\ 22 & & & & & \\ 23 & 25.00 & 28.00 & 0.195 & 1.82 & 33.37 \\ 24 & 25.00 & 35.00 & 0.155 & 1.57 & 33.54 \\ 25 & 50.00 & 35.00 & 0.155 & 1.58 & 33.70 \\ 26 & 100.00 & 35.00 & 0.155 & 1.16 & 37.25 \\ 27 & 150.00 & 35.00 & 0.155 & 0.70 & 41.86 \\ 28 & 200.20 & 35.00 & 0.155 & 0.14 & 48.42 \\ 29 & 250.00 & 35.00 & 0.185 & -0.59 & 57.68 \\ 30 & 300.00 & 35.00 & 0.155 & -1.42 & 74.14 \\ 31 & 350.00 & 35.00 & 0.155 & -3.07 & 112.84 \\ 32 & 395.08 & 35.00 & 0.157 & -7.63 & 283.72 \\ 33 & 412.47 & 35.00 & 0.157 & -10.23 & 569.70 \\ 34 & 421.99 & 35.00 & 0.157 & -7.09 & 623.42 \\ 35 & 432.23 & 35.00 & 0.157 & -3.59 & 534.09\end{array}$




$\begin{array}{ccccc}t /{ }^{\circ} \mathrm{C} & \text { P/MPa } & \text { molality } & \Delta d & \text { V.phi } \\ 25.00 & 1.00 & 0.247 & -0.15 & 34.78 \\ 25.00 & 20.00 & 0.247 & -0.23 & 34.81 \\ 50.00 & 20.00 & 0.249 & -0.44 & 35.99 \\ 100.00 & 20.00 & 0.251 & -0.87 & 38.96 \\ 150.00 & 20.00 & 0.252 & -1.35 & 43.02 \\ 200.20 & 20.00 & 0.254 & -2.01 & 49.20 \\ 250.00 & 20.00 & 0.266 & -2.89 & 58.26 \\ 300.00 & 20.00 & 0.260 & -4.18 & 76.58 \\ 350.00 & 28.00 & 0.258 & -6.19 & 113.69 \\ 379.90 & 28.00 & 0.257 & -13.87 & 278.65 \\ 384.32 & 28.00 & 0.314 & -22.15 & 395.08 \\ 387.18 & 28.00 & 0.235 & -19.98 & 512.91 \\ 390.27 & 28.00 & 0.235 & -24.58 & 736.17 \\ 394.96 & 28.00 & 0.235 & -24.45 & 1119.81 \\ 401.40 & 28.00 & 0.235 & -9.00 & 798.69 \\ 405.73 & 28.00 & 0.234 & -4.91 & 618.65 \\ 412.34 & 28.00 & 0.234 & -2.45 & 478.67 \\ 432.15 & 28.00 & 0.234 & -0.57 & 337.98\end{array}$

$\begin{array}{cc}25.00 & 35.00 \\ 50.00 & 35.00 \\ 100.00 & 35.00 \\ 150.00 & 35.00 \\ 200.20 & 35.00 \\ 250.00 & 35.00 \\ 300.00 & 35.00 \\ 350.00 & 35.00 \\ 395.06 & 35.00 \\ 412.42 & 35.00 \\ 421.83 & 35.00 \\ 432.38 & 35.00\end{array}$

$\begin{array}{ll}0.246 & -0.34 \\ 0.249 & -0.46 \\ 0.250 & -0.81 \\ 0.252 & -1.33 \\ 0.253 & -1.83 \\ 0.267 & -2.58 \\ 0.259 & -3.37 \\ 0.259 & -5.03 \\ 0.234 & -8.70 \\ 0.234 & -11.06 \\ 0.234 & -7.90 \\ 0.234 & -3.98\end{array}$

35.03 35.84 38.43 42.52 47.67 55.24 67.90 97.10 218.17 418.91 467.98 404.77 
$\mathrm{B}(\mathrm{OH}) 3$

Mon, Feb 3, 1992 11:49 PM

\begin{tabular}{|c|c|c|c|c|c|c|c|}
\hline $1 /{ }^{\circ} \mathrm{C}$ & P/MPa & $\Delta \mathrm{d}, 0.2 \mathrm{~m}$ & $V$-phi, $0.2 \mathrm{~m}$ & $\Delta d, \quad 0.5 \mathrm{~m}$ & $V$-phl, $0.5 \mathrm{~m}$ & $\Delta d, 0.75 \mathrm{~m}$ & $V$-phi, $0.75 \mathrm{~m}$ \\
\hline 25.00 & 0.10 & 4.36 & 39.77 & 10.72 & 40.04 & 15.81 & 40.22 \\
\hline 25.00 & 28.00 & 4.28 & 39.95 & 10.57 & 40.11 & 15.67 & 40.18 \\
\hline 25.00 & 10.00 & 4.32 & 39.81 & 10.63 & 40.06 & 15.83 & 40.03 \\
\hline 100.00 & 10.00 & 3.83 & 43.25 & 9.41 & 43.51 & 14.03 & 43.45 \\
\hline 140.68 & 10.50 & 3.67 & 44.93 & & & & \\
\hline 175.11 & 10.00 & 3.73 & 45.39 & 9.11 & 45.82 & 13.60 & 45.73 \\
\hline 250.00 & 10.00 & 3.81 & 46.98 & 9.56 & 46.76 & 14.05 & 47.13 \\
\hline 300.12 & 10.00 & 4.32 & 43.68 & 10.65 & 44.20 & 15.85 & 44.26 \\
\hline 350.00 & 28.00 & 4.94 & 35.53 & 12.04 & 37.09 & 18.08 & 36.76 \\
\hline 380.00 & 28.00 & 8.19 & -35.38 & 19.85 & -28.92 & 29.09 & -24.96 \\
\hline 383.97 & 28.00 & 9.69 & .79 .32 & 23.19 & .67 .26 & 33.69 & .59 .80 \\
\hline 387.13 & 28.00 & 11.71 & -146.73 & 27.78 & -126.10 & 40.02 & -112.80 \\
\hline 390.22 & 28.00 & 14.75 & -272.76 & 34.55 & -232.83 & 49.34 & -207.73 \\
\hline 393.03 & 28.00 & 18.57 & -493.76 & 43.39 & -419.61 & 61.58 & -371.79 \\
\hline 395.10 & 28.00 & 19.85 & -684.38 & 48.57 & .609 .84 & 70.68 & -553.48 \\
\hline 396.95 & 28.00 & 18.45 & -782.35 & 47.29 & .732 .97 & 70.74 & .682 .97 \\
\hline 401.57 & 28.00 & 11.45 & -676.96 & 31.25 & -699.61 & 49.68 & -706.36 \\
\hline 40.5 .70 & 28.00 & 7.73 & -524.10 & 20.67 & -542.09 & 32.88 & -560.60 \\
\hline 412.26 & 28.00 & 5.07 & -374.31 & 13.14 & -378.62 & 20.44 & -388.95 \\
\hline \multirow[t]{2}{*}{432.15} & 28.00 & 2.60 & -168.56 & 6.50 & .160 .15 & 9.89 & -163.79 \\
\hline & & & & & 1 & & \\
\hline 25.00 & 37.00 & 4.30 & 39.78 & 10.61 & 39.96 & 15.78 & 39.96 \\
\hline 100.00 & 35.00 & 3.87 & 42.78 & 9.52 & 43.01 & 14.01 & 43.22 \\
\hline 175.12 & 35.00 & 3.71 & 45.15 & 9.14 & 45.37 & 13.60 & 45.35 \\
\hline 250.00 & 35.00 & 3.76 & 46.81 & 9.23 & 47.20 & 13.83 & 47.01 \\
\hline 300.15 & 35.00 & 3.99 & 46.38 & 9.80 & 46.89 & 14.55 & 46.99 \\
\hline 350.00 & 35.00 & 4.55 & 40.82 & 11.30 & 41.13 & 16.74 & 41.50 \\
\hline 395.28 & 35.00 & 7.25 & -21.23 & 17.73 & -16.74 & 26.21 & .14 .35 \\
\hline 411.98 & 35.00 & 10.27 & $\cdot 178.13$ & 25.10 & -162.21 & 36.96 & -151.72 \\
\hline 421.95 & 35.00 & 9.33 & -277.99 & 23.46 & -265.46 & 35.42 & -258.53 \\
\hline 432.30 & 35.00 & 6.53 & -259.01 & 16.69 & -256.31 & 25.62 & -258.42 \\
\hline
\end{tabular}




\begin{tabular}{|c|c|c|c|c|c|}
\hline & $11^{\circ} \mathrm{C}$ & P/MPa & molality & $\Delta d$ & V.phi \\
\hline 1 & 25.01 & 20.00 & 0.197 & -1.53 & 24.63 \\
\hline 2 & 25.00 & 28.00 & 0.186 & .1 .44 & 24.49 \\
\hline 3 & 100.00 & 10.00 & 0.197 & -1.67 & 26.86 \\
\hline 4 & 109.65 & 10.168 & 0.187 & -1.53 & 26.81 \\
\hline 5 & 120.50 & 10.63 & 0.187 & .1 .59 & 27.24 \\
\hline 6 & 127.60 & 10.50 & 0.187 & .1 .60 & 27.77 \\
\hline 7 & 129.90 & 10.50 & 0.187 & -1.57 & 27.67 \\
\hline 8 & 140.65 & 10.50 & 0.187 & .1 .62 & 28.35 \\
\hline 9 & 175.12 & 10.00 & 0.197 & .1 .78 & 30.21 \\
\hline 10 & 250.00 & 10.00 & 0.197 & -2.06 & 37.30 \\
\hline 11 & 300.15 & 10.00 & 0.197 & -2.59 & 49.66 \\
\hline 12 & 350.00 & 28.00 & 0.196 & -2.91 & 63.56 \\
\hline 13 & 379.90 & 28.00 & 0.196 & -5.42 & 139.51 \\
\hline 14 & 383.85 & 28.00 & 0.191 & .5 .98 & 171.50 \\
\hline 15 & 387.12 & 28.00 & 0.191 & .7 .45 & 231,62 \\
\hline 16 & 390.23 & 28.00 & 0.190 & .9 .11 & 326.75 \\
\hline 17 & 393.00 & 28.00 & 0.190 & -10.38 & 458.46 \\
\hline 18 & 395.09 & 28.00 & 0.190 & -9.84 & 539.90 \\
\hline 19 & 396.95 & 28.00 & 0.190 & -8.0 .7 & 544.49 \\
\hline 20 & 401.43 & 28.00 & 0.189 & .4 .04 & 429.49 \\
\hline 21 & 405.70 & 28.00 & 0.189 & -2.30 & 341.93 \\
\hline 22 & 412.26 & 28.00 & 0.189 & -1.28 & 280.68 \\
\hline 23 & 432.08 & 28.00 & 0.188 & -0.44 & 218.76 \\
\hline 24 & & & & & \\
\hline 25 & 25.00 & 37.00 & 0.197 & -1.52 & 24.35 \\
\hline 26 & 100.00 & 35.00 & 0.197 & -1.67 & 26.45 \\
\hline 27 & 175.13 & 35.00 & 0.197 & -1.75 & 29.36 \\
\hline 28 & 250.00 & 35.00 & 7.87 & -1.99 & 35.23 \\
\hline 29 & 300.12 & 35.00 & 0.197 & .2 .05 & 40.68 \\
\hline 30 & 3.50 .00 & 35.00 & 0.196 & .2 .62 & 56.83 \\
\hline 31 & 395.28 & 3500 & 0.187 & -3.88 & 116.90 \\
\hline 32 & 412.56 & 35.00 & 0.188 & -4.95 & 226.08 \\
\hline 33 & 422.03 & 35.00 & 0.188 & -3.66 & 259.94 \\
\hline 34 & 432.17 & 35.00 & 0.188 & -2.09 & 2.40 .29 \\
\hline 35 & & & & & \\
\hline 36 & & & & & \\
\hline 37 & 25.00 & 0.10 & 0.398 & .3 .03 & 24.80 \\
\hline 38 & 25.00 & 20.00 & 0.398 & $-3,18$ & 24.99 \\
\hline 39 & 25.00 & 28.00 & 0.366 & -2.76 & 24.34 \\
\hline 40 & 109.68 & 10.68 & 0.369 & -3.09 & 27.05 \\
\hline 41 & 350.00 & 28.00 & 0.394 & -5.79 & 63.51 \\
\hline 42 & 379.90 & 28.00 & 0.394 & .10 .80 & 140.12 \\
\hline 43 & 383.95 & 28.00 & 0.379 & .12 .36 & 179.41 \\
\hline 44 & 387.12 & 28.00 & 0.378 & -15.02 & 238.89 \\
\hline 45 & 390.23 & 28.00 & 0.378 & -18.33 & 338.13 \\
\hline 46 & 393.00 & 28.00 & 0.378 & .20 .64 & 475.32 \\
\hline 47 & 395.09 & 28.00 & 0.377 & .18 .73 & 534.31 \\
\hline 48 & 396.95 & 28.00 & 0.377 & .15 .35 & 539.16 \\
\hline 49 & 401.43 & 28.00 & 0.376 & .7 .80 & 425.87 \\
\hline 50 & 405.70 & 28.00 & 0.375 & .4 .60 & 347.19 \\
\hline 51 & 412.26 & 28.00 & 0.375 & -2.63 & 283.31 \\
\hline 52 & 432.08 & 28.00 & 0.374 & -0.96 & 229.96 \\
\hline 53 & & & & & \\
\hline 54 & 25.00 & 35.00 & 0.398 & .3 .14 & 24.57 \\
\hline 55 & 395.28 & 35.00 & 0.372 & .7 .77 & 198.55 \\
\hline 56 & 412.56 & 35.00 & 0.373 & -9.78 & 227.84 \\
\hline
\end{tabular}


$11^{\circ} \mathrm{C}$ P/MPa molality $\Delta d \quad$ V.phl

\begin{tabular}{|c|c|c|c|c|c|}
\hline 57 & 422.03 & 35.00 & 0.373 & -7.21 & 261.29 \\
\hline 58 & 432.17 & 35.00 & 0.374 & -4.10 & 239.80 \\
\hline \multicolumn{6}{|l|}{59} \\
\hline \multicolumn{6}{|l|}{60} \\
\hline 61 & 25.00 & 0.10 & 0.810 & .6 .08 & 24.80 \\
\hline 62 & 25.01 & 20.00 & 0.811 & -6.34 & 24.82 \\
\hline 63 & 99.99 & 10.00 & 0.811 & -6.78 & 26.90 \\
\hline 64 & 175.10 & 10.00 & 0.811 & .7 .30 & 30.38 \\
\hline 65 & 250.00 & 10.00 & 0.811 & .8 .48 & 37.64 \\
\hline 66 & 300.13 & 10.00 & 0.811 & -10.81 & 50.66 \\
\hline 67 & 350.00 & 28.00 & 0.800 & -12.01 & 64.93 \\
\hline 68 & 379.90 & 28.00 & 0.799 & -22.86 & 100.82 \\
\hline 63 & 383.96 & 28.00 & 0.779 & -26.18 & 189.39 \\
\hline 70 & 387.12 & 28.00 & 0.779 & -32.35 & 258.11 \\
\hline 79 & 390.24 & 28.00 & 0.778 & -38.70 & 364.47 \\
\hline 72 & 393.08 & 28.00 & 0.777 & .41 .07 & 490.98 \\
\hline 73 & 395.05 & 28.00 & 0.776 & .36 .30 & 534.63 \\
\hline 74 & 396.95 & 2.8 .00 & 0.776 & -28.86 & 522.52 \\
\hline 75 & 401.45 & 28.00 & 0.773 & -15.02 & 415.48 \\
\hline 76 & 405.70 & 28.00 & 0.772 & -9.05 & 342.54 \\
\hline 77 & 412.27 & 28.00 & 0.772 & -5.32 & 290.02 \\
\hline 78 & 432.08 & 28.00 & 0.779 & -2.04 & 235.11 \\
\hline \multicolumn{6}{|l|}{79} \\
\hline 80 & 25.00 & 28.00 & 0.762 & .5 .89 & 24.60 \\
\hline 81 & 25.00 & 37.00 & 0.811 & .6 .15 & 24.35 \\
\hline 82 & 100.00 & 35.00 & 0.811 & .6 .75 & 26.45 \\
\hline B3 & 175.12 & 35.00 & 0.811 & -7.17 & 29.51 \\
\hline 84 & 250.00 & 35.00 & 0.811 & -7.78 & 34.77 \\
\hline 85 & 300.13 & 35.00 & 0.811 & -8.78 & 41.84 \\
\hline 86 & 350.00 & 35.00 & 0.799 & -10.66 & 57.48 \\
\hline 87 & 395.28 & 35.00 & 0.768 & .16 .37 & 122.40 \\
\hline 88 & 412.37 & 35.00 & 0.768 & -19.77 & 228.96 \\
\hline 89 & 422.07 & 35.00 & 0.769 & .94 .29 & 259.83 \\
\hline 90 & 432.35 & 35.00 & 0.770 & -8.16 & 239.18 \\
\hline \multicolumn{6}{|l|}{91} \\
\hline \multicolumn{6}{|l|}{92} \\
\hline 93 & 25.00 & 0.10 & 1.564 & -11.64 & 24.86 \\
\hline 94 & 25.01 & 20.00 & 1.565 & -11.81 & 24.68 \\
\hline 95 & 99.99 & 10.00 & 1.565 & .13 .02 & 27.02 \\
\hline 96 & 109.75 & 10.68 & 1.493 & .12 .40 & 27.25 \\
\hline 97 & 175.10 & 10.00 & 1.565 & -14.17 & 30.68 \\
\hline 98 & 250.00 & 10.00 & 1.565 & .16 .30 & 37.94 \\
\hline 99 & 300.16 & 10.00 & 1.565 & .20 .96 & 51.52 \\
\hline 100 & 350.00 & 28.00 & 1.550 & .23 .42 & 66.39 \\
\hline 101 & 380.00 & 28.00 & 1.549 & .48 .03 & 166.38 \\
\hline 102 & 383.97 & 28.00 & 1.514 & -56.03 & 219.09 \\
\hline 103 & 387.14 & 28.00 & 1.514 & .67 .94 & 301.11 \\
\hline 104 & 390.22 & 28.00 & 1.512 & .76 .57 & 411.71 \\
\hline 105 & 393.08 & 28.00 & 1.511 & .73 .79 & 508.44 \\
\hline 106 & 395.04 & 28.00 & 1.510 & .61 .80 & 519.82 \\
\hline 107 & 396.95 & 28.00 & 1.510 & .48 .63 & 497.28 \\
\hline 108 & 401.46 & 28.00 & 1.506 & .26 .23 & 400.26 \\
\hline 109 & 405.71 & 28.00 & 1.504 & .16 .35 & 335.40 \\
\hline 110 & 412.27 & 28.00 & 1.504 & -9.85 & 287.29 \\
\hline 111 & 4.32 .28 & 28.00 & 1.504 & .4 .00 & 239.54 \\
\hline
\end{tabular}


NH3

\begin{tabular}{|c|c|c|c|c|c|}
\hline & $11^{\circ} \mathrm{C}$ & P/MPa & molality & $\Delta d$ & V-phi \\
\hline 113 & 25.00 & 28.00 & 1.494 & -11.40 & 24.64 \\
\hline 114 & 25.00 & 37.00 & 1.565 & -12.26 & 24.74 \\
\hline 115 & 100.00 & 35.00 & 1.565 & -12.85 & 26.49 \\
\hline 116 & 175.12 & 35.00 & 1.565 & -13.75 & 29.66 \\
\hline 117 & 250.02 & 35.00 & 1.565 & -15.15 & 35.21 \\
\hline 118 & 300.12 & 35.00 & 1.565 & .17 .05 & 42.41 \\
\hline 119 & 350.00 & 35.00 & 1.549 & -20.92 & 58.80 \\
\hline 120 & 395.28 & 35.00 & 1.498 & -32.16 & 127.16 \\
\hline 121 & 412.46 & 35.00 & 1.500 & -37.16 & 234.02 \\
\hline 122 & 421.97 & 35.00 & 1.501 & -26.30 & 257.71 \\
\hline 123 & 432.24 & 35.00 & 1.502 & -15.55 & 241.76 \\
\hline \multicolumn{6}{|l|}{124} \\
\hline \multicolumn{6}{|l|}{125} \\
\hline 126 & 25.00 & 0.10 & 2.960 & -21.61 & 24.80 \\
\hline 127 & 25.01 & 20.00 & 2.962 & -21.65 & 24.69 \\
\hline 128 & 120.50 & 10.63 & 2.680 & .21 .64 & 27.58 \\
\hline 129 & 127.60 & 10.50 & 2.680 & -21.76 & 27.87 \\
\hline 130 & 129.90 & 10.50 & 2.680 & $" 21.83$ & 27.98 \\
\hline 131 & 140.70 & 10.50 & 2.680 & -22.22 & 28.54 \\
\hline 132 & 350.00 & 28.00 & 2.920 & .43 .29 & 35.26 \\
\hline 133 & 379.90 & 28.00 & 2.920 & .91 .45 & 184.94 \\
\hline 134 & 383.97 & 28.00 & 2.780 & -105.35 & 252.64 \\
\hline 135 & 387.14 & 28.00 & 2.780 & -120.72 & 339.64 \\
\hline 136 & 390.23 & 28.00 & 2.770 & -124.40 & 431.93 \\
\hline 137 & 393.03 & 28.00 & 2.770 & -110.55 & 484.18 \\
\hline 138 & 395.04 & 28.00 & 2.770 & -90.06 & 475.11 \\
\hline 139 & 396.94 & 28.00 & 2.760 & .71 .16 & 452.31 \\
\hline 140 & 401.35 & 28.00 & 2.750 & .40 .23 & 369.49 \\
\hline 141 & 405.72 & 28.00 & 2.740 & -25.88 & 317.67 \\
\hline 142. & 412.29 & 28.00 & 2.740 & .15 .81 & 273.46 \\
\hline 143 & 432.18 & 28.00 & 2.730 & -6.59 & 232.07 \\
\hline \multicolumn{6}{|l|}{144} \\
\hline 145 & 25.00 & 28.00 & 3.106 & -22.43 & 24.51 \\
\hline 146 & 25.00 & 37.00 & 2.962 & -21.99 & 24.58 \\
\hline 147 & 350.00 & 35.00 & 2.920 & -37.60 & 58.84 \\
\hline 148 & 395.27 & 35.00 & 2.710 & .58 .60 & 135.44 \\
\hline 149 & 412.52 & 35.00 & 2.720 & .61 .56 & 235.06 \\
\hline 150 & 421.95 & 35.00 & 2.720 & -42.57 & 250.71 \\
\hline 151 & 432.50 & 35.00 & 2.730 & -24.53 & 92.67 \\
\hline
\end{tabular}




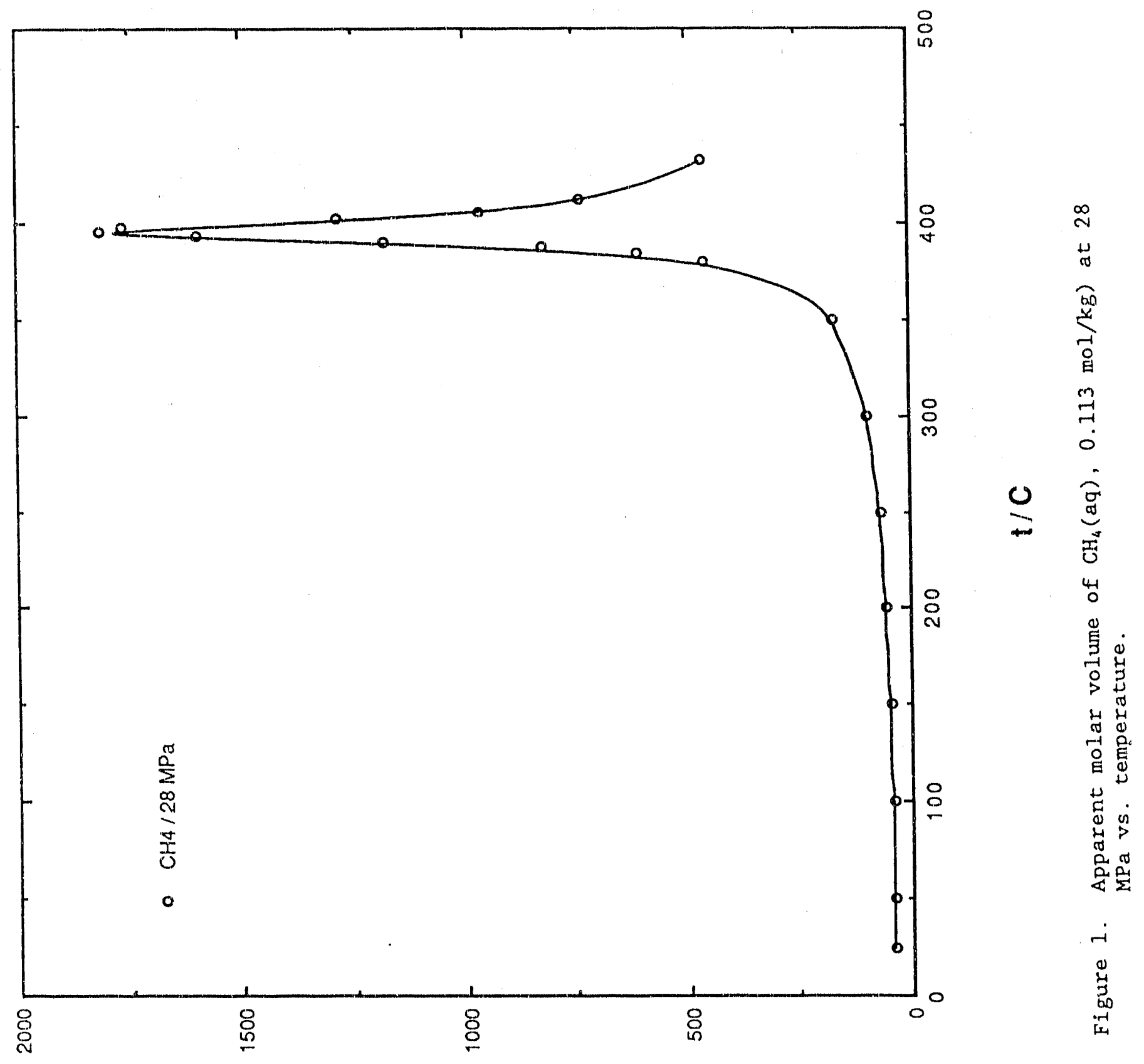

amnion sepow fuasedde 


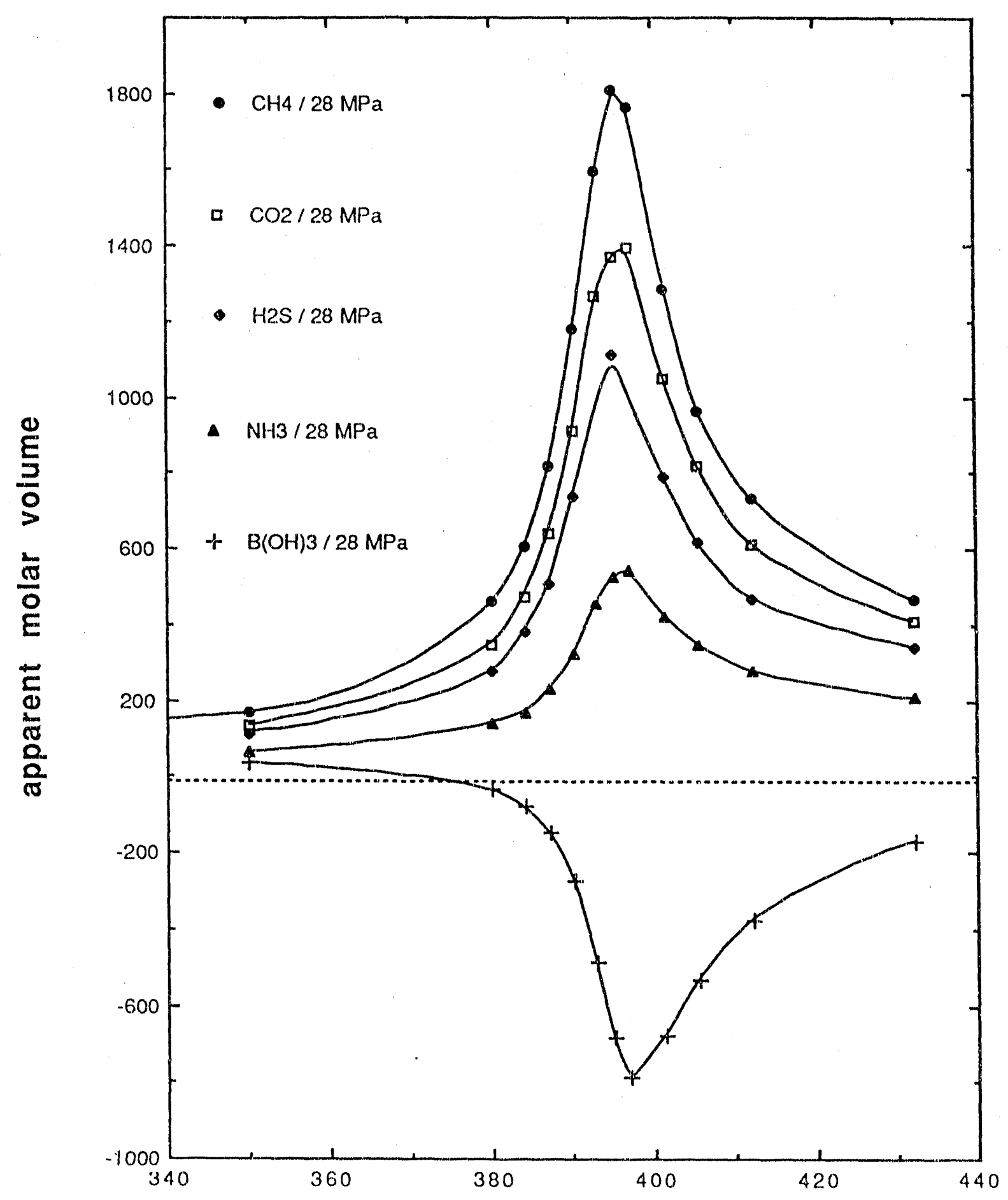

$t / C$

Figure 2. Apparent molar volume of $\mathrm{CH}_{4}$ (aq, $0.113 \mathrm{~mol} / \mathrm{kg}$ ), $\mathrm{CO}_{2}$ (aq, 0.115 $\mathrm{mol} / \mathrm{kg}), \mathrm{H}_{2} \mathrm{~S}(\mathrm{aq}, 0.235 \mathrm{~mol} / \mathrm{kg}), \mathrm{NH}_{3}(\mathrm{aq}, 0.2 \mathrm{~mol} / \mathrm{kg})$, and $\mathrm{B}(\mathrm{OH})_{3}(\mathrm{aq}, 0.2$ mol $/ \mathrm{kg}$ ) at $28 \mathrm{MPa}$ vs. temperature. 


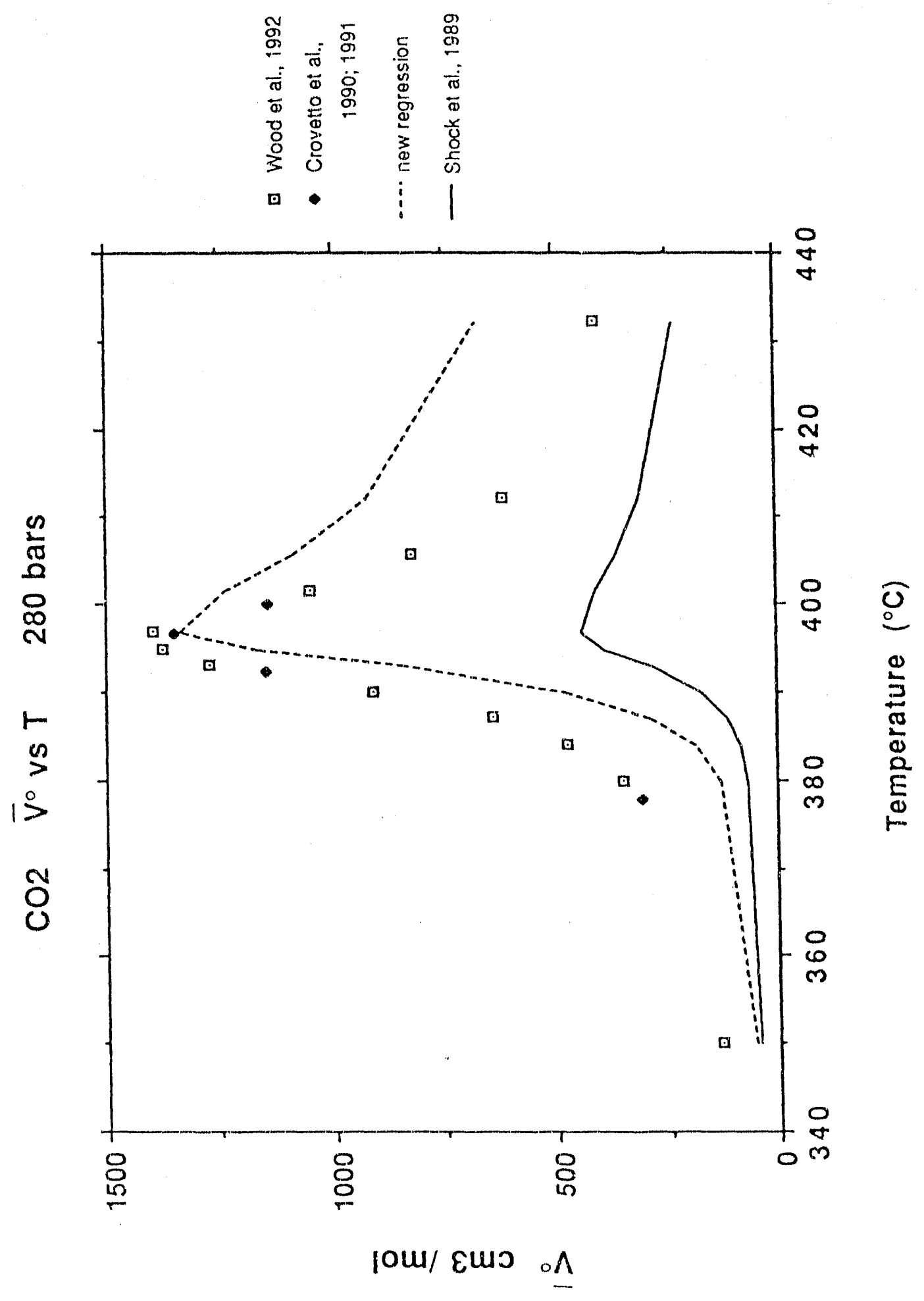

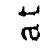

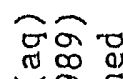

i $\frac{1}{10}$

넘

मू तु

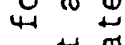

$\therefore$ 它常

स है 4

0 응

क ज 5

矛 $E$ 엄

$>4$ 告

r in 0

d

동

E

- 5 तो

o w is

ช

ह

어

동

돈

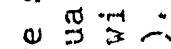

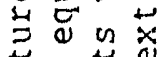

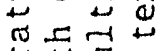

$\alpha, \pi$ is 0

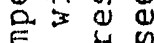

E 0 .

- 5

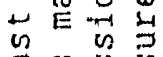

Eथ 的

등 出

bo.r bo 4

获出

吕导导

4 两

0 口.

เ

ब.

is 0

ल

D正?

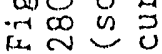




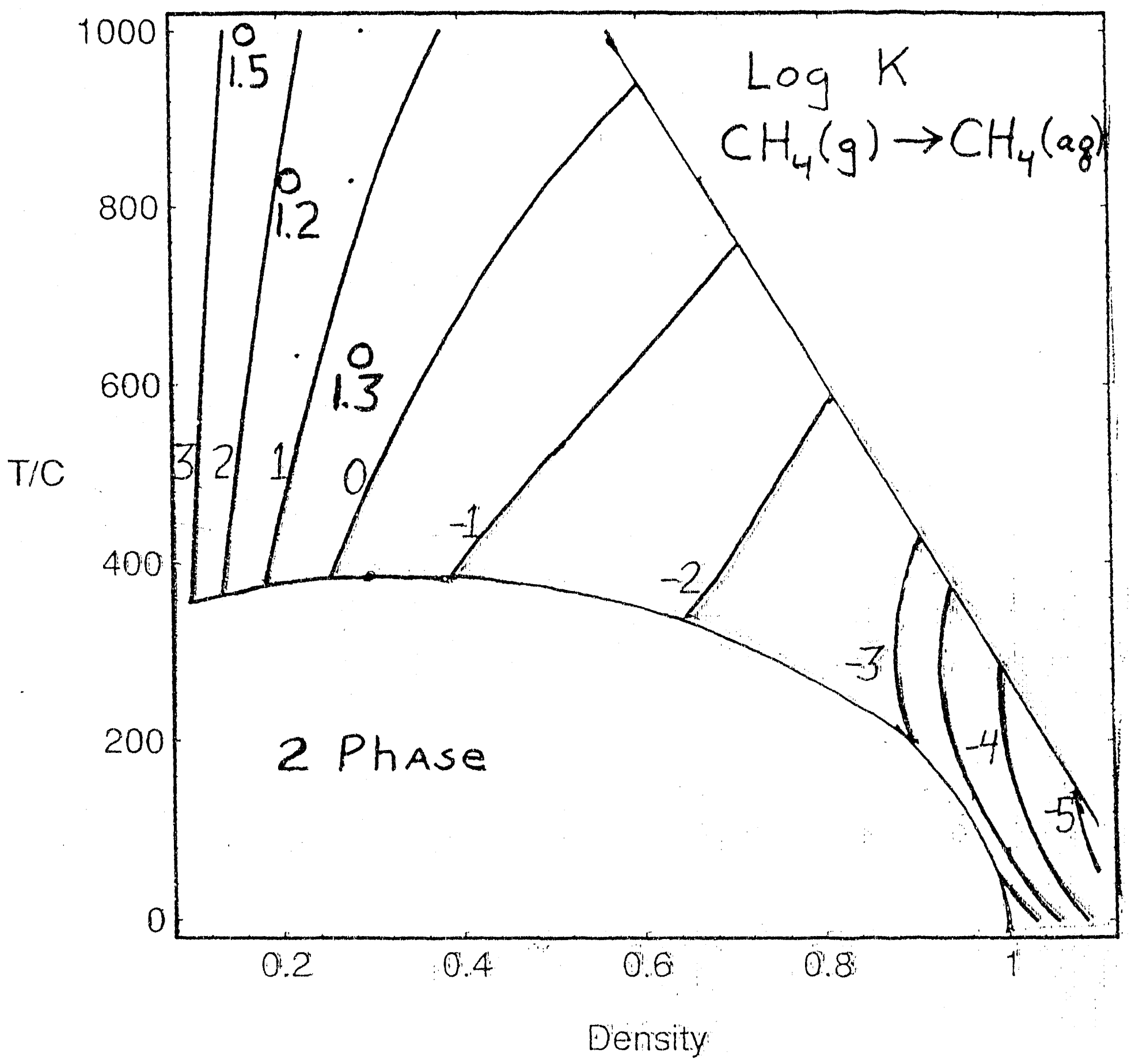

Fig. 4. Contour plot of $\mathrm{Log} \mathrm{K}$ for $\mathrm{CH}_{4}(\mathrm{~g}) \rightarrow \mathrm{CH}_{4}(\mathrm{aq})$ vs. $\mathrm{T}$ and density of water. Points are results from preliminary simulations. Contour lines are the predictions of SUPCRT92 (Johnson et al., 1991) based on Shock and Helgeson (1990). 


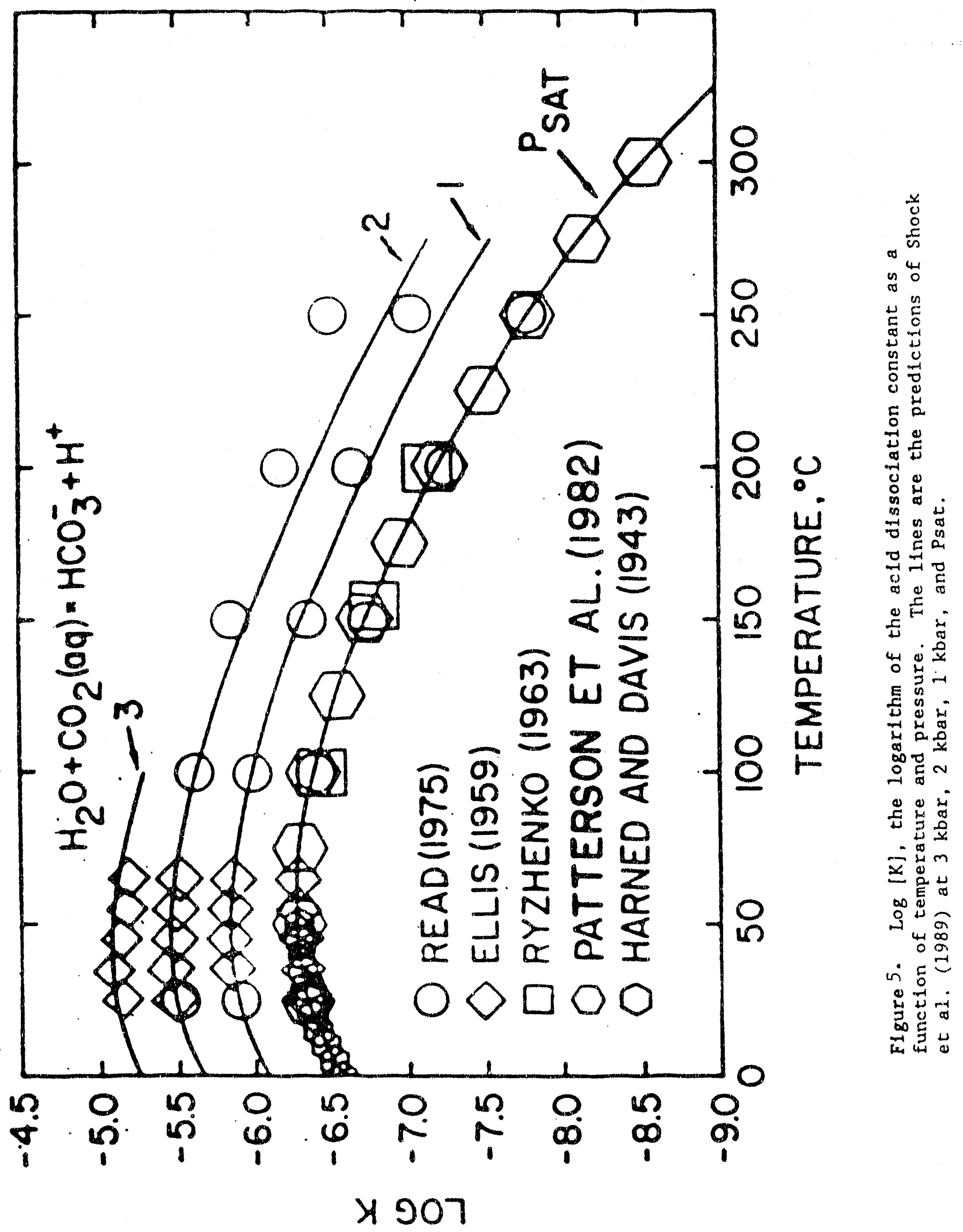



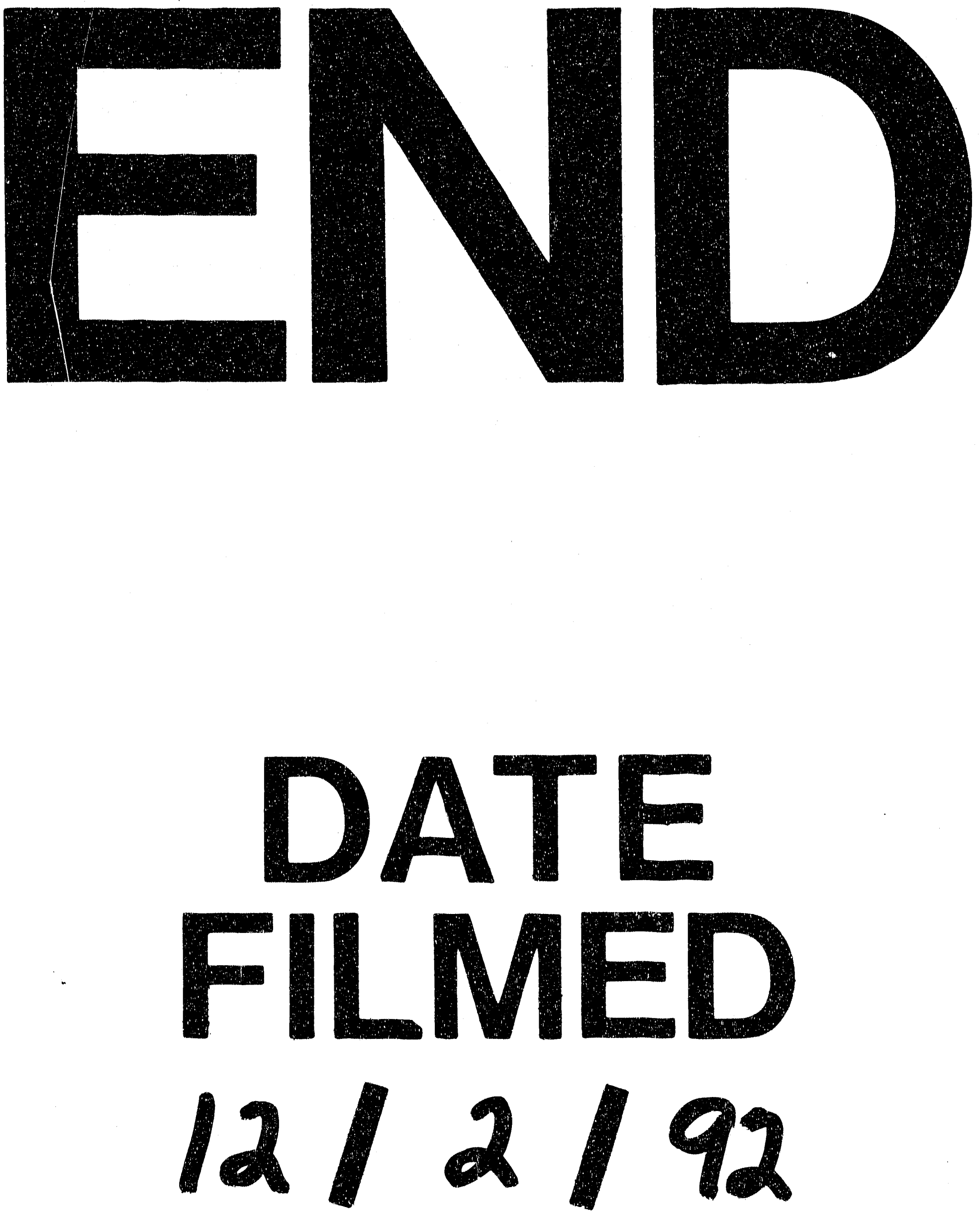
